\title{
Mapeamento de Pesquisas Sobre Tecnostress em Professores de Matemática
}

\author{
Mapeamiento de Investigaciones Sobre Tecnostress en Profesores de \\ Matemática
}

Mapping of Research on Tecnostress in Math Teachers

\author{
Fabrine Diniz Pereira ${ }^{1}$ \\ Thaís Philipsen Grützmann²
}

Tanise Paula Novello ${ }^{3}$

\begin{abstract}
Resumo
As inovações tecnológicas vêm transformando os ambientes sociais e de trabalho, nesse contexto, surge a necessidade de se promover espaços de discussão sobre os impactos causados pelas mudanças que as tecnologias digitais causam no cotidiano profissional dos professores, pois estes podem trazer sentimentos negativos àqueles que ainda têm um estranhamento frente às ferramentas tecnológicas, especialmente as digitais. Emerge então, o termo tecnostress que é conceituado como um estado psicológico negativo relacionado com o uso de tecnologias da informação e comunicação (TIC) ou com a ameaça de seu uso futuro. Com esse entendimento, o presente trabalho parte do desejo investigativo de mapear os estudos acadêmicos realizados no âmbito de dissertações, teses e artigos sobre o tecnostress em professores de Matemática. Observou-se que no Brasil, as pesquisas acadêmicas e científicas relacionadas ao estudo do tecnostress são deficitárias, ainda que, represente uma temática pertinente ao contexto da docência na atualidade, o que reafirma a necessidade de fomentar pesquisas sobre o tecnostress na docência por meio de programas de pós-graduação, pois estas podem contribuir para a promoção de estratégias que visem o bem-estar dos professores na era digital.
\end{abstract}

Palavras-Chave: Matemática; Professor; Tecnologias; Tecnostress.

\section{Resumen}

Las innovaciones tecnológicas vienen transformando los ambientes sociales y de trabajo, en ese contexto, surge la necesidad de promover espacios de discusión sobre los impactos causados por los cambios que las tecnologías digitales causan en el cotidiano profesional de los profesores, pues éstos pueden traer sentimientos negativos a aquellos que aún tienen un extrañamiento frente a las herramientas tecnológicas, especialmente las digitales. Se emerge entonces, el término tecnostress que es conceptuado como un estado psicológico negativo relacionado con el uso de tecnologías de la información y comunicación (TIC) o con la amenaza de su uso futuro. Con este entendimiento, el presente trabajo parte del deseo investigativo de mapear los estudios académicos realizados en el ámbito de disertaciones, tesis y artículos sobre el tecnostress en profesores de Matemática. Se observó que en Brasil, las investigaciones académicas y científicas relacionadas al estudio del tecnostress son deficitarias, aunque, represente una temática pertinente al contexto de la docencia en la actualidad, lo que reafirma la necesidad de fomentar investigaciones sobre el tecnostress en la docencia por medio de programas de postgrado, ya que éstos pueden contribuir a la promoción de estrategias para el bienestar de los profesores en la era digital.

\footnotetext{
${ }^{1}$ Mestranda do Programa de Pós-graduação em Educação Matemática; Universidade Federal de Pelotas; Pelotas, Rio Grande do Sul, Brasil; fabrinediniz@ hotmail.com

2 Doutora em Educação; Universidade Federal de Pelotas; Pelotas, Rio Grande do Sul, Brasil; thaisclmd2@gmail.com

${ }^{3}$ Doutora em Educação Ambiental; Universidade Federal do Rio Grande - FURG; Rio Grande, Rio Grande do Sul, Brasil; tanisenovello@furg.br
} 
Palabras claves: Matemática; Profesor; Tecnologías; Tecnostress.

\begin{abstract}
Technological innovations have been transforming social and work environments. In this context, there is a need to promote spaces for discussion on the impacts caused by the changes that digital technologies cause in teachers' professional daily life, since these can bring negative feelings to those who still have an estrangement from technological tools, especially digital ones. It emerges, then, the term technostress that is conceptualized as a negative psychological state related to the use of information and communication technologies (ICT) or with the threat of its future use. With this understanding, the present work starts from the investigative desire to map the academic studies carried out in the scope of dissertations, theses and articles on the technostress in Mathematics teachers. It was observed that in Brazil, academic and scientific research related to the study of the technostress are deficient, although, it represents a thematic pertinent to the context of teaching nowadays, which reaffirms the need to promote research on the technostress in teaching through postgraduate programs, since these can contribute to the promotion of strategies aimed at the well-being of teachers in the digital era.
\end{abstract}

Keywords: Mathematics; Teacher; Technologies; Tecnostress.

\title{
1. Introdução
}

$\mathrm{Na}$ sociedade atual, configurada tecnologicamente, a gestão do conhecimento é remodelada constantemente. Cada vez mais, multiplicam-se as fontes de produção de informações e esse é o mundo real para o qual a escola forma os alunos, por essa razão, estáse percebendo que o ambiente escolar necessita entrar em sincronia com a Era Digital. Assim, para se pensar em uma outra configuração de escola, não basta garantir uma infraestrutura tecnológica eficiente, é preciso formar professores que deem conta da dinâmica entre o saber e aos alunos, de modo a desenvolver competências necessárias à resolução de problemas do mundo real. Nesse sentido, a fim desenvolver uma estratégia que potencialize integrar tecnologias à educação, é preciso levar em consideração a cultura digital em que hoje se vive de que forma ela influencia as demais culturas e grupos. Para Lemos e Lévy (2010), a cultura digital é uma forma sociocultural que possibilita a mudança nos hábitos sociais, nas práticas de consumo e produção cultura, o que potencializa novas relações de trabalho e de lazer, outras configurações na sociabilidade e na comunicação social pelo operar das tecnologias digitais.

A cultura digital, caracterizada pelas relações que se podem estabelecer entre homens e máquinas, também é denominada por Lévy (2010) como cibercultura, e a define como um "conjunto de técnicas, de práticas, de atitudes, de modos de pensamento e de valores que se desenvolvem juntamente com o crescimento do ciberespaço" (p. 17). A cultura digital também envolve o compartilhamento de informações, sejam elas músicas, arquivos de texto, vídeos ou imagens, veiculadas e transmitidas por vários centros. Isso significa dizer que hoje a informação não percorre somente uma direção linear e vertical, as pessoas imersas na cultura digital leem e escrevem com várias tecnologias, incluindo textos, ferramentas digitais, 
mídia social de diferentes formatos e frequentemente as utilizam de forma combinada, pois é por essas vias que o conhecimento circula na era digital.

Segundo Buckinghan (2000), a infância contemporânea está permeada pela mídia moderna, através da televisão, do vídeo, dos jogos de computador, da Internet, da telefonia móvel, da música popular e pelo leque de commodities (mercadorias) ligadas à mídia que formam a cultura do consumo contemporâneo. Essa cultura se aproxima de outros termos como cibercultura, era digital, sociedade da informação e, cada um deles, é descrito para demarcar esta época na qual as relações humanas têm sido fortemente mediadas pela tecnologia digital. Os adolescentes deste século, utilizam dispositivos digitais desde o despertar, para verificar o clima que os espera na rua, para ouvir músicas durante o trajeto até a escola e até mesmo no momento de lazer, optando, muitas vezes, em navegar na internet como forma de descanso. Cada interface que surge legitima outros processos sociais e a digitalização do mundo está transformando todos os setores da sociedade, em maior ou menor grau.

Don Tapscott (2009) desenvolveu um estudo sobre as representações da "Geração Eletrônica" que corresponde às crianças e adolescentes nascidos desde meados da década de 1990, período no qual a efervescência de parafernálias digitais passou a fazer parte do cotidiano dos jovens norte-americanos:

Oito características, ou normas, descrevem um típico sujeito da Geração Digital e os diferenciam dos seus pais, os boomers. Eles prezam a liberdade e a liberdade de escolha. Eles querem personalizar as coisas, tornando-as próprias. Eles são colaboradores naturais, que gostam de uma conversa, não de palestras. Eles irão analisar minuciosamente você e a sua empresa. Insistem na integridade. Eles querem se divertir, mesmo no trabalho ou na escola. Velocidade é algo normal. A inovação é parte da vida. (TAPSCOTT, 2009, p. 6)

Outra questão a se destacar é o fato de que hoje as crianças passam a desempenhar o papel de professores, ensinando aos adultos o manejo com as tecnologias digitais, ferramentas nas quais estão imersas desde o nascimento. Por conta da capacidade que os jovens possuem de distribuir atenção sob diversas interfaces, a realização de tarefas simultâneas (multitarefas) seria o marcador que os diferenciam dos indivíduos de outras gerações.

Mark Prensky (2001) sugeriu uma escala cronológica em que o mundo marcado pelas tecnologias seria dividido entre os nativos e os imigrantes digitais. A geração digital, identificados como "multitarefas" se destaca por uma intensa relação com os aparatos tecnológicos, o que resultou no seu domínio. Para Prensky (2001) essa fluência com os artefatos, transformou esses sujeitos em especialistas digitais, possuidores de uma capacidade múltipla, ou seja, aptos a utilizar diversas mídias ao mesmo tempo. Por esse motivo o autor 
classifica-os como nativos digitais, em oposição aos seus pais e professores que, em sua maioria, nasceram antes e que, portanto, seriam os imigrantes digitais.

Diante das dinâmicas transformações sociais promovidas pela evolução tecnológica, a escola está sem saber como e quais competências devem ser desenvolvidas nas crianças e jovens imersos na cultura digital, para que se desenvolvam nesta nova era educativa. Essas dúvidas são latentes, pois as novas gerações cresceram imersas na tecnologia digital tendo os eletrônicos e a internet como parte fundamental de sua vida. Estes não conheceram o mundo sem a interatividade que a tecnologia digital permite e, por isso, pensam e processam a informação de maneira diferente das gerações anteriores. Nesse contexto, surge a necessidade de se promover espaços de discussão sobre o impacto que as mudanças tecnológicas trazem ao cotidiano dos professores, pois estas podem trazer sentimentos negativos àqueles que ainda têm um estranhamento frente às ferramentas tecnológicas, especialmente as digitais.

Essas mudanças e inovações tecnológicas podem produzir problemas físicos, psíquicos e sociais com consequências à saúde do trabalhador, isso porque o trabalho com tecnologias digitais requer maior exigência cognitiva com sobrecarga em seus processos mentais (CARLOTTO, 2011). Nesse sentido, emerge o termo tecnostress que é conceituado por Salanova (2003) e Carlotto (2011) como um estado psicológico negativo relacionado com o uso de tecnologias digitais ou com a ameaça de seu uso futuro. Com esse entendimento, o presente estudo parte do desejo investigativo de mapear os estudos acadêmicos realizados no âmbito de dissertações, teses e artigos sobre o tecnostress em professores de Matemática. $\mathrm{Na}$ próxima sessão, será explanada a metodologia utilizada para o levantamento dos estudos.

\section{Percurso Metodológico}

Para a realização deste estudo, em que pesquisamos dissertações, teses e artigos que abordam a temática "Tecnostress em professores de Matemática" produzidos entre os anos de 2013 a 2018, optamos por um percurso investigativo de caráter qualitativo, buscando evidenciar o estado do conhecimento de Ferreira (2002). Esta é uma opção metodológica que procura o compreender de determinada temática por meio de sua sistematização e análise. Segundo Haddad (2002), o estado do conhecimento permite um recorte temporal definido, além da sistematização do campo pretendido, a identificação de abordagens dominantes e emergentes, a análise crítica das produções acadêmicas, bem como permite destacar as lacunas ou os campos inexplorados abertos às pesquisas futuras. Ferreira (2002), diz que as pesquisas denominadas "estado da arte" ou "estado do conhecimento" nos últimos 15 anos no Brasil parecem trazer em comum o desafio de mapear e de discutir uma certa produção 
acadêmica em diferentes campos do conhecimento, tentando responder que aspectos e dimensões vêm sendo destacados e privilegiados em diferentes épocas e lugares, de que formas e em que condições têm sido produzidas certas dissertações de mestrados e teses de doutorado, publicações em periódicos e comunicações em anais de congressos e seminários. Na figura a seguir é evidenciada a sistematização dos caminhos metodológicos percorridos para a realização do estado do conhecimento.

\section{SISTEMATIZAÇÃO DOS CAMINHOS METODOLÓGIOS}

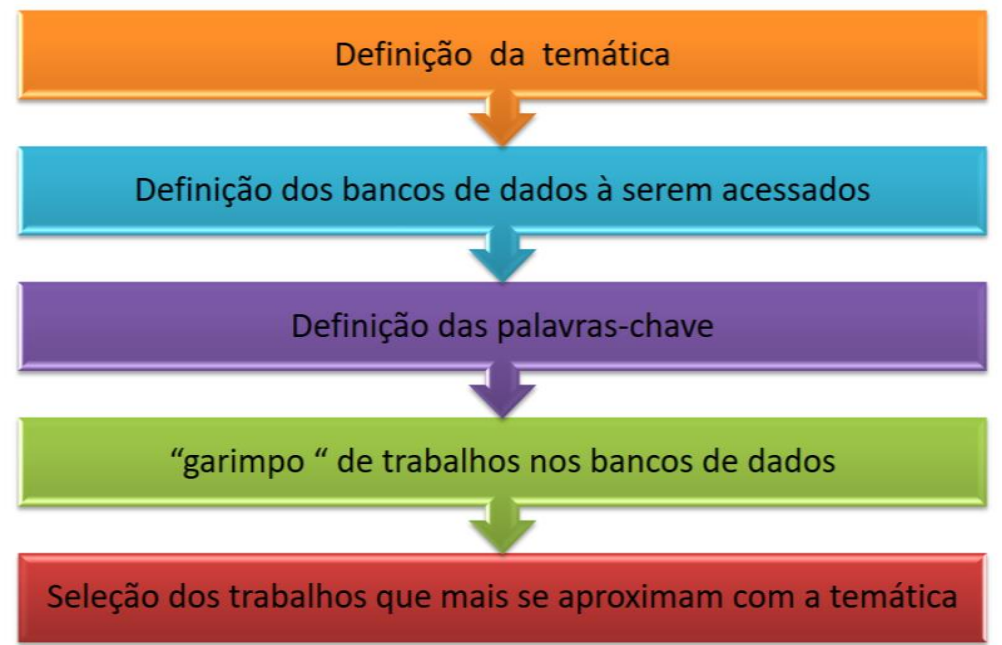

Figura 1 - Sistematização da metodologia.

Fonte: As autoras (2018).

Compreendendo essa proposta, e considerando que os avanços tecnológicos contribuem para o fácil acesso a fontes de informação, é possível ter acesso aos bancos de dados digitais. Com isso, optamos por fazer o levantamento de dissertações e teses no site da Biblioteca Digital Brasileira de Teses e Dissertações (BDTD) ${ }^{4}$, de artigos publicados nas revistas Bolema ${ }^{5}$ e Zetetiké ${ }^{6}$, e nos anais dos eventos: Associação Nacional de Pós-Graduação e Pesquisa em Educação (ANPEd) ${ }^{7}$, Encontro Nacional de Educação Matemática (ENEM) ${ }^{8}$,

\footnotetext{
${ }^{4}$ Disponível em: http://bdtd.ibict.br

${ }^{5}$ Disponível em: http://www.periodicos.rc.biblioteca.unesp.br

${ }^{6}$ Disponível em: https://periodicos.sbu.unicamp.br

${ }^{7}$ Disponível em: http://www.anped.org.br/

${ }^{8}$ Disponível em: http://www.sbembrasil.org.br/sbembrasil/index.php/anais/enem
} 
Seminário Internacional de Pesquisa em Educação Matemática (SIPEM) ${ }^{9}$ e Congresso IberoAmericano de Educação Matemática $(\mathrm{CIBEM})^{10}$.

Após a definição do percurso da pesquisa, definimos algumas palavras-chave que constassem no título dos trabalhos, a fim de assegurar alguma semelhança com a temática em questão. As palavras-chave utilizadas durante as buscas nos sites acima definidos foram: tecnostress; tecnoestresse; stress e tecnologia; estresse e tecnologia; mal estar e tecnologia; dificuldades e tecnologia; impactos, escola e tecnologia. A seguir, serão expostos os resultados obtidos deste levantamento, bem como a discussão dos mesmos.

\section{Seleção dos trabalhos correlatos à temática}

O levantamento inicial foi feito no site da Biblioteca Digital Brasileira de Teses e Dissertações (BDTD). Primeiramente se buscou por "tecnostress" e "tecnoestresse", escritas em inglês e em português, respectivamente, pois poderiam ser encontrados trabalhos com ambas as grafias. Essa busca foi feita no título e no assunto dos trabalhos, sendo que esta varredura resultou em uma tese. Em seguida buscamos por "stress e tecnologia" e "estresse e tecnologia", resultando em uma dissertação e uma tese. Com as palavras-chave "mal estar e tecnologia" encontramos uma tese e com as palavras-chave "dificuldades e tecnologia" encontramos quatro trabalhos, sendo cinco dissertações e uma tese. Por fim, encontramos três trabalhos utilizando as palavras-chave "impactos, escola e tecnologia", sendo duas dissertações e uma tese. Contudo, deste primeiro processo de seleção das pesquisas, encontramos um total de 11 trabalhos, conforme descritos no quadro a seguir:

Tabela 1 - Mapeamento de dissertações e teses.

\begin{tabular}{|c|c|c|c|c|c|}
\hline Título & Autor/a & $\begin{array}{l}\text { Programa de Pós- } \\
\text { Graduação }\end{array}$ & IES & $\mathbf{D} / \mathbf{T}$ & Orientador/a \\
\hline $\begin{array}{l}\text { Qualidade de vida no trabalho (QVT), } \\
\text { bem-estar/mal-estar no trabalho e } \\
\text { reconversão tecnológica: } \\
\text { representações de trabalhadores em } \\
\text { empresa pública brasileira }\end{array}$ & $\begin{array}{l}\text { Pacheco, } \\
\text { Veruska } \\
\text { Albuquerque }\end{array}$ & $\begin{array}{l}\text { Psicologia Social, } \\
\text { do Trabalho e das } \\
\text { Organizações }\end{array}$ & $\begin{array}{l}\text { Universidade de } \\
\text { Brasília }\end{array}$ & $\mathrm{T}$ & $\begin{array}{l}\text { Ferreira, Mário } \\
\text { César }\end{array}$ \\
\hline $\begin{array}{c}\text { Planejamento estratégico } \\
\text { em tecnologia da informação: um } \\
\text { estudo sobre as dificuldades para } \\
\text { implantação em uma instituição de } \\
\text { ensino superior }\end{array}$ & $\begin{array}{l}\text { Martins, Alan } \\
\text { dos Santos }\end{array}$ & $\begin{array}{l}\text { Administração da } \\
\text { Escola de } \\
\text { Administração }\end{array}$ & $\begin{array}{l}\text { Universidade } \\
\text { Federal da } \\
\text { Bahia }\end{array}$ & $\mathrm{D}$ & $\begin{array}{c}\text { Hastenreiter Filho, } \\
\text { Horacio Nelson }\end{array}$ \\
\hline $\begin{array}{l}\text { Avaliando tecnologia de ensino de } \\
\text { leitura e escrita informatizada e }\end{array}$ & Tizo, & Ciências do & $\begin{array}{l}\text { Universidade } \\
\text { Federal de }\end{array}$ & $\mathrm{T}$ & Hanna, Elenice \\
\hline
\end{tabular}

\footnotetext{
${ }^{9}$ Disponível em: http://www.sbem.com.br/visipem/

${ }^{10}$ Disponível em: http://www.cibem7.semur.edu.uy
} 
RELACult - Revista Latino-Americana de Estudos em Cultura e Sociedade

Revista Latinoamericana de Estudios en Cultura y Sociedad | Latin American Journal of Studies in Culture and Society V. 05, ed. especial, abr., 2019, artigo n ${ }^{\circ} 1233$ | claec.org/relacult | e-ISSN: 2525-7870

\begin{tabular}{|c|c|c|c|c|c|}
\hline $\begin{array}{l}\text { adaptada para alunos de escola pública } \\
\text { com dificuldade de aprendizagem }\end{array}$ & Marcileyde & Comportamento & Brasília & & Seixas \\
\hline $\begin{array}{c}\text { Techno-stress entre profissionais } \\
\text { da tecnologia informacional }\end{array}$ & $\begin{array}{l}\text { Ferreira, } \\
\text { Emanuel José } \\
\text { Rebouças }\end{array}$ & $\begin{array}{l}\text { Engenharia de } \\
\text { Produção }\end{array}$ & $\begin{array}{l}\text { Universidade } \\
\text { Federal de Santa } \\
\text { Catarina }\end{array}$ & $\mathrm{T}$ & $\begin{array}{l}\text { Casarotto Filho, } \\
\text { Nelson }\end{array}$ \\
\hline $\begin{array}{c}\text { Psicossomática e tecnologia: stress em } \\
\text { jogadores de lan house }\end{array}$ & $\begin{array}{c}\text { Freitas, } \\
\text { Cláudia } \\
\text { Guimarães } \\
\text { Gonçalves }\end{array}$ & $\begin{array}{l}\text { Psicologia: } \\
\text { Psicologia Clínica }\end{array}$ & $\begin{array}{c}\text { Pontifícia } \\
\text { Universidade } \\
\text { Católica de São } \\
\text { Paulo }\end{array}$ & $\mathrm{D}$ & $\begin{array}{l}\text { Vasconcellos, } \\
\text { Esdras Guerreiro }\end{array}$ \\
\hline $\begin{array}{c}\text { Inovação tecnológica e a lei federal n. } \\
10.973 / 2004 \text { dificuldades legais e } \\
\text { fáticas }\end{array}$ & $\begin{array}{l}\text { Ripari, } \\
\text { Vanessa } \\
\text { Toqueiro }\end{array}$ & $\begin{array}{l}\text { Mestrado em } \\
\text { Direito }\end{array}$ & $\begin{array}{l}\text { Universidade } \\
\text { Nove de Julho }\end{array}$ & $\mathrm{D}$ & $\begin{array}{l}\text { Moro, Maitê } \\
\text { Cecilia Fabbri }\end{array}$ \\
\hline $\begin{array}{l}\text { A utilização das Tecnologias da } \\
\text { Informação e Comunicação pelos } \\
\text { docentes de enfermagem e as } \\
\text { dificuldades no processo de ensino- } \\
\text { aprendizagem }\end{array}$ & $\begin{array}{l}\text { Leite, Kamila } \\
\text { Nethielly } \\
\text { Souza }\end{array}$ & Enfermagem & $\begin{array}{l}\text { Universidade } \\
\text { Federal da } \\
\text { Paraíba }\end{array}$ & $\mathrm{D}$ & $\begin{array}{l}\text { Leite, Kamila } \\
\text { Nethielly Souza }\end{array}$ \\
\hline $\begin{array}{c}\text { Impactos, dificuldades e avanços na } \\
\text { inserção de tecnologias na cultura } \\
\text { escolar }\end{array}$ & $\begin{array}{l}\text { Silva, Raul } \\
\text { César da }\end{array}$ & Educação & $\begin{array}{l}\text { Universidade } \\
\text { Estadual do } \\
\text { Oeste do Paraná }\end{array}$ & $\mathrm{D}$ & $\begin{array}{l}\text { Francischett, } \\
\text { Mafalda Nesi }\end{array}$ \\
\hline $\begin{array}{c}\text { A integração das tecnologias à } \\
\text { licenciatura em Matemática: } \\
\text { Percepções do professor sobre } \\
\text { dificuldades e desafios para a } \\
\text { formação inicial }\end{array}$ & $\begin{array}{l}\text { Silva, } \\
\text { Elivelton } \\
\text { Serafim }\end{array}$ & $\begin{array}{c}\text { Ensino de Ciências } \\
\text { e Educação } \\
\text { Matemática }\end{array}$ & $\begin{array}{l}\text { Universidade } \\
\text { Estadual da } \\
\text { Paraíba }\end{array}$ & $\mathrm{D}$ & $\begin{array}{c}\text { Andrade, Silvanio } \\
\text { de }\end{array}$ \\
\hline $\begin{array}{l}\text { Educação escolar e mediação: } \\
\text { impactos das tecnologias digitais no } \\
\text { processo de formação }\end{array}$ & $\begin{array}{l}\text { Santos, Elaine } \\
\text { Cristina } \\
\text { Moraes }\end{array}$ & Educação & $\begin{array}{l}\text { Universidade } \\
\text { Estadual } \\
\text { Paulista }\end{array}$ & $\mathrm{D}$ & $\begin{array}{c}\text { Lastória, Luíz } \\
\text { Antônio Calmon } \\
\text { Nabuco }\end{array}$ \\
\hline $\begin{array}{c}\text { A utilização de } \\
\text { instrumentos tecnológicos no } \\
\text { cotidiano escolar: condições, } \\
\text { interações, possibilidades e impactos } \\
\text { nas relações de ensino }\end{array}$ & $\begin{array}{c}\text { Camargo, } \\
\text { Andréia } \\
\text { Regina de } \\
\text { Oliveira }\end{array}$ & Educação & $\begin{array}{l}\text { Universidade } \\
\text { Estadual de } \\
\text { Campinas. }\end{array}$ & $\mathrm{T}$ & $\begin{array}{c}\text { Smolka, Ana } \\
\text { Luiza Bustamante }\end{array}$ \\
\hline
\end{tabular}

Fonte: As autoras (2018).

Após a leitura dos resumos descartamos sete trabalhos, pois constatamos que: uma pesquisa tratava de tecnostress, porém não abordava a área do ensino ou da educação; uma pesquisa travava sobre stress sem aproximação com o ensinar e o aprender; uma pesquisa falava em bem-estar em profissionais não ligados à educação; uma pesquisa tratava de inovação tecnológica sem se aproximar da temática investigada; outra pesquisa tinha foco em docentes da enfermagem e a última pesquisa descartada focava na implementação de tecnologia nos setores administrativos de uma Instituição de Ensino Superior. 
Nas revistas e anais dos eventos pré-determinados anteriormente, não foram encontrados trabalhos com as palavras-chave que definimos. Este fato aponta a escassez de pesquisas sobre a temática "Tecnostress: o stress oriundo das tecnologias digitais dos professores de matemática", o que reafirma a relevância deste trabalho.

Sendo assim, para realizar o mapeamento proposto neste estudo, foram utilizados como material de análise um total de quatro trabalhos (três dissertações e uma tese), descritos no quadro a seguir:

Tabela 2: Dissertações e teses selecionadas

\begin{tabular}{|c|c|c|c|c|c|}
\hline Título & Autor/a & $\begin{array}{l}\text { Programa de Pós- } \\
\text { Graduação }\end{array}$ & IES & $\mathbf{D} / \mathbf{T}$ & Orientador/a \\
\hline $\begin{array}{c}\text { Impactos, dificuldades e avanços na } \\
\text { inserção de tecnologias na cultura } \\
\text { escolar }\end{array}$ & $\begin{array}{l}\text { Silva, Raul } \\
\text { César da }\end{array}$ & Educação & $\begin{array}{l}\text { Universidade } \\
\text { Estadual do } \\
\text { Oeste do Paraná }\end{array}$ & $\mathrm{D}$ & $\begin{array}{l}\text { Francischett, } \\
\text { Mafalda Nesi }\end{array}$ \\
\hline $\begin{array}{c}\text { A integração das tecnologias à } \\
\text { licenciatura em Matemática: } \\
\text { Percepções do professor sobre } \\
\text { dificuldades e desafios para a } \\
\text { formação inicial }\end{array}$ & $\begin{array}{l}\text { Silva, } \\
\text { Elivelton } \\
\text { Serafim }\end{array}$ & $\begin{array}{l}\text { Ensino de Ciências } \\
\text { e Educação } \\
\text { Matemática }\end{array}$ & $\begin{array}{l}\text { Universidade } \\
\text { Estadual da } \\
\text { Paraíba }\end{array}$ & $\mathrm{D}$ & $\begin{array}{c}\text { Andrade, Silvanio } \\
\text { de }\end{array}$ \\
\hline $\begin{array}{l}\text { Educação escolar e mediação: } \\
\text { impactos das tecnologias digitais no } \\
\text { processo de formação }\end{array}$ & $\begin{array}{l}\text { Santos, Elaine } \\
\text { Cristina } \\
\text { Moraes }\end{array}$ & Educação & $\begin{array}{l}\text { Universidade } \\
\text { Estadual } \\
\text { Paulista } \\
\text { (UNESP) }\end{array}$ & $\mathrm{D}$ & $\begin{array}{l}\text { Lastória, Luíz } \\
\text { Antônio Calmon } \\
\text { Nabuco }\end{array}$ \\
\hline $\begin{array}{c}\text { A utilização de } \\
\text { instrumentos tecnológicos no } \\
\text { cotidiano escolar : condições, } \\
\text { interações, possibilidades e impactos } \\
\text { nas relações de ensino }\end{array}$ & $\begin{array}{l}\text { Camargo, } \\
\text { Andréia } \\
\text { Regina de } \\
\text { Oliveira }\end{array}$ & Educação & $\begin{array}{l}\text { Universidade } \\
\text { Estadual de } \\
\text { Campinas. }\end{array}$ & $\mathrm{T}$ & $\begin{array}{c}\text { Smolka, Ana } \\
\text { Luiza Bustamante }\end{array}$ \\
\hline
\end{tabular}

Fonte: As autoras (2018).

Em seguida, apresenta-se uma breve descrição sobre cada um dos registros encontrados.

\section{Dissertação 1: Impactos, dificuldades e avanços na inserção de tecnologias na cultura escolar}

Esta dissertação foi defendida no ano de 2014 e foi baseada nas experiências de escolas públicas estaduais do Paraná e realizada em três escolas de Ensino Médio do município de Francisco Beltrão. O autor procurou identificar como têm disso utilizados os recursos tecnológicos disponíveis da escola, as limitações e dificuldades no uso destes instrumentos, bem como foi abordada a diferença no uso e domínio destes recursos entre 
professores e alunos. Buscou-se ampliar o debate para questões curriculares e sociais que interferem no processo de ensinar e aprender.

O autor diz que com o advento e acesso as tecnologias digitais, as escolas estão diante de nova realidade, cujo potencial e o papel educacional necessitam de reflexões. Ele diz ainda que há de se considerar a influência que as mídias de massa exercem sobre os alunos, e os impactos que são claramente percebidos na relação dos alunos com o conhecimento. Mesmo com as iniciativas governamentais e de professores para encontrar o lugar e o papel das tecnologias na educação, segundo o autor estas esbarram em limites pessoais, institucionais, e carência de aprofundamento teórico. Nesse sentido, o autor sugere que investir em processo de formações continuadas dos professores são fundamentais para este debate.

\section{Dissertação 2: A integração das tecnologias à licenciatura em Matemática: percepções do professor sobre dificuldades e desafios para a formação inicial.}

Este trabalho foi defendido no ano de 2017 e discute a formação inicial do professor de matemática, focando o papel do professor formador das disciplinas de Educação Matemática Aplicada à Tecnologia. $\mathrm{O}$ autor aborda a integração da tecnologia nos processos de ensinar e aprender nos cursos de licenciatura em matemática e, em particular, por analisar as percepções dos professores formadores em sua prática docente. $\mathrm{O}$ autor enfatiza que foi possível observar que os professores, em sua maioria, defendem que durante a formação inicial do professor de matemática, tenha contato com o maior número possível de ferramentas tecnológicas, assim como, inferem que sejam destinados momentos para o estudo teórico e outros para o desenvolvimento de ações práticas, relacionadas com o uso de tecnologias em sala de aula.

Outro aspecto apontado pelo autor consiste em que os professores formadores pouco evidenciaram as práticas voltadas para a formação de um intelectual transformador tomando por base o contexto das tecnologias digitais. A partir disso, o autor conclui que o estudo teórico é indispensável, porém que na disciplina analisada é dada mais ênfase para as atividades práticas. Entretanto, não apenas a prática do formador da disciplina, mas as discussões desenvolvidas pela linha de tecnologias em Educação Matemática se distanciam dos aspectos relacionados à formação de um intelectual transformador.

\section{Dissertação 3: Educação escolar e mediação: impactos das tecnologias digitais no processo de formação}


Neste trabalho, defendido no ano de 2014, considera-se a difusão das tecnologias digitais na sociedade contemporânea, assim como, sua expansão no ambiente escolar e tem como categoria de análise, o processo de mediação, como o caminho para problematizar, que tipo de conhecimento estes recursos digitais são capazes de promover. Segundo a autora, considerando o papel da prática escolar na sociedade, bem como sobre os mecanismos ideológicos que ocultam a principal finalidade dos fenômenos tecnológicos, este estudo contém a seguinte hipótese: a forma com que as tecnologias digitais estão inseridas nas atuais políticas educacionais inviabiliza uma mediação pedagógica emancipadora, gerando impactos evidentemente enfrentados na prática escolar e na formação humana.

\section{Tese: A utilização de instrumentos tecnológicos no cotidiano escolar: condições, interações, possibilidades e impactos nas relações de ensino}

Esta tese foi defendida em 2013 e buscou analisar condições, interações e impactos relacionados à integração dos instrumentos tecnológicos nas relações de ensino. A partir de interlocuções estabelecidas entre professores, gestores e alunos no desenvolvimento de um projeto de intervenção no ambiente escolar, procurou-se acompanhar o trabalho dos professores via seminários, sugerir atividades, realizar oficinas, explorando diversas experiências e possibilidades de trabalho com recursos tecnológicos, observando e registrando o desenvolvimento do projeto, que se efetivou em uma vivência participativa. As formas de interação e participação, as atividades significativas, a mediação do professor e da pesquisadora, os resultados e produtos do trabalho realizado, foram discutidos e compartilhados, buscando-se relacionar os pressupostos teóricos da perspectiva HistóricoCultural assumida e a prática cotidiana dos professores em exercício, que experienciavam as possibilidades de integração das tecnologias no processo de ensinar e aprender. Através do desenvolvimento da pesquisa a autora observou que a apropriação e a utilização de instrumentos tecnológicos possibilitam o redimensionamento da prática educativa.

\section{Análise dos trabalhos selecionados}

O levantamento e análise desses quatro estudos permitiu observar que não existem pesquisas no âmbito de programas de Pós-Graduação com foco no tecnostress em docentes, tão pouco em professores de Matemática, podendo apenas, evidenciar alguns trabalhos com temáticas correlatas que se aproximam à temática investigada, sendo que apenas um trabalho 
tem foco em licenciandos em Matemática. É possível que a carência de trabalhos sobre a temática esteja relacionada ao fato de que o estudo sobre tecnostress é relativamente recente, tendo surgido a partir de um trabalho feito pelo psiquiatra americano Craig Brod, em meados dos anos 80, quando ocorreu a expansão dos laptops nos Estados Unidos, registrando que $10 \%$ a $15 \%$ da população americana sofre desse mal-estar que passou a ser considerada um problema de saúde pública.

Já no Brasil, o tecnostress começou a surgir por volta dos anos 90, quando as pessoas começaram a ter mais acesso à internet, aos notebooks e aos celulares; entretanto, a sociedade ainda não vê o tecnostress como doença, mas sim como um vício tecnológico, o que dificulta o diagnóstico para um tratamento eficaz. Todavia, é possível observar que alguns aspectos evidenciados nos trabalhos se relacionam com as dimensões que podem causar o tecnostress. Silva (2014) diz que o acesso as tecnologias digitais colocam as escolas diante de nova realidade, cujo potencial e o papel educacional necessitam de reflexões, pois o trabalho docente está diretamente relacionado a jovens nativos digitais, que são aqueles que nasceram e cresceram convivendo com as inovações tecnológicas e usam desde cedo computadores, videogames, reprodutores de música, câmeras de vídeo e celulares, além de outros brinquedos e ferramentas da era digital (PRENSKY, 2001). Porém ainda se tem um considerável percentual de docentes que ainda tem um estranhamento com as tecnologias digitais, ou seja, nasceram e se desenvolveram sem a presença dos artefatos tecnológicos, e por consequência, estão em um processo de inserção e aprendizagem de uma nova linguagem e de outra lógica, sendo caracterizados como imigrantes digitais (PRENSKY, 2001).

Outro aspecto abordado por Santos (2014) foi a inviabilização da mediação pedagógica emancipadora, gerada pela forma com que se utiliza as tecnologias digitais no ambiente escolar, o que segundo a autora, gera impactos na prática escolar e na formação humana. Esses impactos, bem como as dificuldades e desafios na utilização das tecnologias digitais como potencial pedagógicos, relatados em todos os trabalhos, podem causar sentimentos negativos aos professores, frente às tecnologias digitais, podendo estes ficarem vulneráveis aos sintomas do tecnostress, pois para Lipp e Malagris (2003) toda mudança que exige adaptação por parte do organismo causa certo nível de estresse, por envolver algum tipo de perda, principalmente quando abrange a natureza do trabalho.

Todas estas questões, sobretudo a escassez de pesquisas sobre a temática "Tecnostress em professores de matemática", reafirmam a relevância deste trabalho. Por isso reitera-se a necessidade de fomentar pesquisas sobre o tecnostress na docência por meio de programas de pós-graduação. 


\section{Conclusões}

O desenvolvimento do presente trabalho possibilitou o mapeamento de pesquisas correlatas a temática "tecnostress em professores de Matemática", na qual se evidenciou a falta de pesquisas no âmbito de programas de Pós-Graduação com foco no tecnostress em docentes. Foi encontrado apenas um trabalho com foco em licenciandos em Matemática que se aproximava com o tema investigado, porém em todos os trabalhos pode-se observar aspectos que vão ao encontro das dimensões do tecnostress, o que evidencia que os professores estão propensos a desenvolver os sintomas do stress oriundo das tecnologias digitais.

Contudo, salientamos que, no Brasil, as pesquisas acadêmicas e científicas relacionadas ao estudo do tecnostress são deficitárias, ainda que, represente uma temática pertinente ao contexto da docência na atualidade. Ainda assim, acredita-se que este fato, torna-se um incentivo para dar continuidade a pesquisas sobre esta temática, pois estas contribuem para o desenvolvimento de estratégias que visem o bem-estar docente na era digital.

\section{Referências}

CAMARGO, A. R. O. A utilização de instrumentos tecnológicos no cotidiano escolar: condições, interações, possibilidades e impactos nas relações de ensino. 106f. Tese (doutorado). Universidade Estadual de Campinas. Campinas. 2013. Disponível em: < http://repositorio.unicamp.br/bitstream/REPOSIP/250795/1/Camargo_AndreiaReginadeOlivei ra_M.pdf > Acesso em: 15 dez. 2018.

FERREIRA, N. S. A. As Pesquisas Denominadas "Estados da Arte”. Educação \& Sociedade, Campinas, n. 79, p. 257-272, agosto/2002.

HADDAD, S. Juventude e escolarização: uma análise da produção de conhecimentos. Brasília, DF: MEC/Inep/Comped, 2002.

LEMOS, A. LÉVY, P. O futuro da internet: em direção a uma ciberdemocracia planetária. São Paulo: Paulus, 2010.

LÉVY, P. Cibercultura. São Paulo: Editora 34, 2010.

LIPP, M. N.; MALAGRIS, L. N. Stress. São Paulo: Contexto, 2003.

PRENSKY, M. Digital Natives, Digital Immigrants. MCB University Press, Bradford, v. 9, n 5, 2001. Disponível em: <http://www.marcprensky.com/writing/Prensky\%20\%20Digital\%20Natives,\%20Digital\%20Immigrants\%20-\%20Part1.pdf >. Acesso em: 2 ago. 2018. 
SALANOVA, M. Trabajando com tecnologías y afrontando El tecnoestrés: El rol de las creencias de eficacia. Revista de Psicología del Trabajo y de lãs Organizaciones, v. 19, n. 3, p. 225-246, 2003.

SANTOS, E. C. M. Educação escolar e mediação: impactos das tecnologias digitais no processo de formação. 87f. Dissertação (mestrado) - Universidade Estadual Paulista. Araraquara. $2014 . \quad$ Disponível em:

https://repositorio.unesp.br/bitstream/handle/11449/123862/000828990.pdf?sequence=1\&isAl lowed=y > Acesso em: 12 dez. 2018.

SILVA, E. S. A integração das tecnologias à licenciatura em matemática: percepções do professor formador sobre dificuldades e desafios para a formação inicial. 199f. Dissertação (mestrado) - Universidade da Paraíba, Campina Grande, 2017. Disponível em: < http://tede.bc.uepb.edu.br/jspui/handle/tede/2768> Acesso em: 12 dez. 2018.

SILVA, R. C. Impactos, dificuldades e avanços na inserção de tecnologias na cultura escolar. 2014, 106 f. Dissertação (Mestrado) - Programa de Mestrado em Educação, Universidade Estadual do Oeste do Paraná, Francisco Beltrão, 2014.

TAPSCOTT, D. Grown up digital: how the net generation is changing your world. New York: McGraw-Hill, 2009. 